\title{
The Emerging Role and Promise of Circular RNAs in Obesity and Related Metabolic Disorders
}

\author{
Mohamed Zaiou 1,2 (iD \\ 1 School of Pharmacy, The University of Lorraine, 7 Avenue de la Foret de Haye, \\ CEDEX BP 90170, F-54500 Vandoeuvre-les-Nancy, France; mohamed.zaiou@univ-lorraine.fr; \\ Tel.: +3303-7277-90-15; Fax: +3303-8368-23-01 \\ 2 Institut Jean Lamour, UMR 7198, CNRS, The University of Lorraine, 2 allée André Guinier, BP 50840, \\ 54011 Nancy, France
}

Received: 26 May 2020; Accepted: 11 June 2020; Published: 16 June 2020

\begin{abstract}
Circular RNAs (circRNAs) are genome transcripts that are produced from back-splicing of specific regions of pre-mRNA. These single-stranded RNA molecules are widely expressed across diverse phyla and many of them are stable and evolutionary conserved between species. Growing evidence suggests that many circRNAs function as master regulators of gene expression by influencing both transcription and translation processes. Mechanistically, circRNAs are predicted to act as endogenous microRNA (miRNA) sponges, interact with functional RNA-binding proteins (RBPs), and associate with elements of the transcriptional machinery in the nucleus. Evidence is mounting that dysregulation of circRNAs is closely related to the occurrence of a range of diseases including cancer and metabolic diseases. Indeed, there are several reports implicating circRNAs in cardiovascular diseases (CVD), diabetes, hypertension, and atherosclerosis. However, there is very little research addressing the potential role of these RNA transcripts in the occurrence and development of obesity. Emerging data from in vitro and in vivo studies suggest that circRNAs are novel players in adipogenesis, white adipose browning, obesity, obesity-induced inflammation, and insulin resistance. This study explores the current state of knowledge on circRNAs regulating molecular processes associated with adipogenesis and obesity, highlights some of the challenges encountered while studying circRNAs and suggests some perspectives for future research directions in this exciting field of study.
\end{abstract}

Keywords: circular RNAs (circRNAs); adipogenesis; epigenetics; cardiovascular diseases; microRNAs (miRNAs); insulin resistance; adipose tissue browning

\section{Introduction}

Whole-genome sequencing studies reveal that our genome comprises approximately 3 to 3.2 billion base pairs of DNA, but merely 1-2\% of those pairs correspond to the annotated exons of protein-coding genes. The remaining $98-99 \%$ have been referred to as "junk DNA" or "dark matter" with no obvious function in the cell [1]. Currently, major scientific advances in the field that have occurred upon implementation of novel and sensitive molecular approaches to genome-wide transcriptome analysis [2], have totally changed the way we look at the vast "noncoding" regions of the human genome. What was once considered "junk DNA" because of its lack of function is now viewed as a treasure. It is becoming known from multiple studies that junk DNA can be almost entirely transcribed, generating a huge number of functional transcripts commonly referred to as noncoding RNAs (ncRNAs) although many of their functions remain enigmatic [3,4]. According to the biological functions of ncRNAs, they can be classified into infrastructural and regulatory types. Infrastructural ncRNAs include ribosomal RNAs (rRNAs), transfer RNAs (tRNAs), and small nuclear RNAs (snRNAs) 
and are typically expressed constitutively, whereas regulatory ncRNAs consist mainly of microRNAs (miRNAs), long noncoding RNAs (lncRNAs), circular RNAs (circRNAs), and piwi-interacting RNAs (piRNAs). Inconsistent with the "central dogma of biology" that describes the flow of genetic information from gene to mRNA and finally to protein, ncRNAs are generally not further translated into proteins [5]. Although they do not encode proteins, these RNA molecules can still be endowed with critical regulatory function and may help orchestrate a hidden layer of gene regulation networks [6]. As a matter of fact, circumstantial evidence revealed that ncRNAs can act as critical switches that fine-tune target gene expression $[7,8]$. From a clinical perspective, several transcriptomic studies have unveiled that a large number of ncRNAs can be altered in major diseases [9] clearly hinting towards the potential therapeutic application of these RNA molecules in disease therapy.

As stated before, there are different types of ncRNA transcriptomes with varied functions; among the most relevant are small ncRNAs such as miRNAs (18-24 nucleotides (nt.)), lncRNAs (>200 nt.), and circRNAs (median length is $\sim 530 \mathrm{nt}$.). In recent years, considerable attention has focused on circRNAs, which are distinguished from their linear counterparts by the unique structure of covalently closed continuous loop lacking $5^{\prime}$ cap and $3^{\prime}$ poly-adenylated tails [10]. This feature makes circRNAs remarkably stable and resistant to degradation by exonuclease and RNases, therefore, they are proposed as new generation of predictive biomarkers and potential therapeutic targets for many diseases. Even though evidence of their biological relevance and clinical significance in human disease pathogenesis is continuously emerging, our current knowledge of circRNAs remains preliminary in metabolic diseases and obesity in particular. Additionally, to the very best of my knowledge, there is hardly any comprehensive coverage on the role of circRNAs in the pathogenesis of obesity. Hence, the next sections will discuss relevant literature in the field and highlight some of the key aspects of circRNAs and challenges ahead.

\section{Landscape of circRNAs}

\subsection{Biogenesis of circRNAs}

Contrary to conventional splicing forming a linear RNA, circRNAs are generally derived from precursor mRNA back-splicing, a molecular event in which a downstream $5^{\prime}$ splice site is joined to a downstream $3^{\prime}$ splice site to form a covalently closed circular structure [11]. Even though the specific and detailed mechanisms mediating circRNAs biogenesis are not fully understood, several models have been proposed, including direct back-splicing with Arthrobacter luteus (ALU) elements and inverted repeats complementation, lariat-driven circularization (exon skipping), and RNA-binding-protein (RBP) mediated models [12]. Based on their sequences, circRNAs can be generally classified into three categories: i) exonic circRNAs (EcircRNAs), which are generated only from the exon regions, account for most (over $80 \%$ ) known circRNAs, and are found mainly in the cytoplasm; ii) circRNAs derived from lariat introns (ciRNAs) predominantly located in nuclei; and iii) circRNAs derived from exons with retained introns (EIciRNAs) and can be mainly found in nuclei $[10,11,13]$ (Figure 1). Previous analysis of the number of circRNAs from their host genes revealed that one gene could produce multiple circRNA isoforms, with nearly $50 \%$ of the host genes expressing one circRNA at significantly higher levels [14]. Concerning circRNAs turnover, exosomes have been proposed as one of the mechanisms by which these transcripts might be cleared from the cell [15], but further studies are required to explore the regulatory factors involved in the control of circRNAs metabolic turnover. 


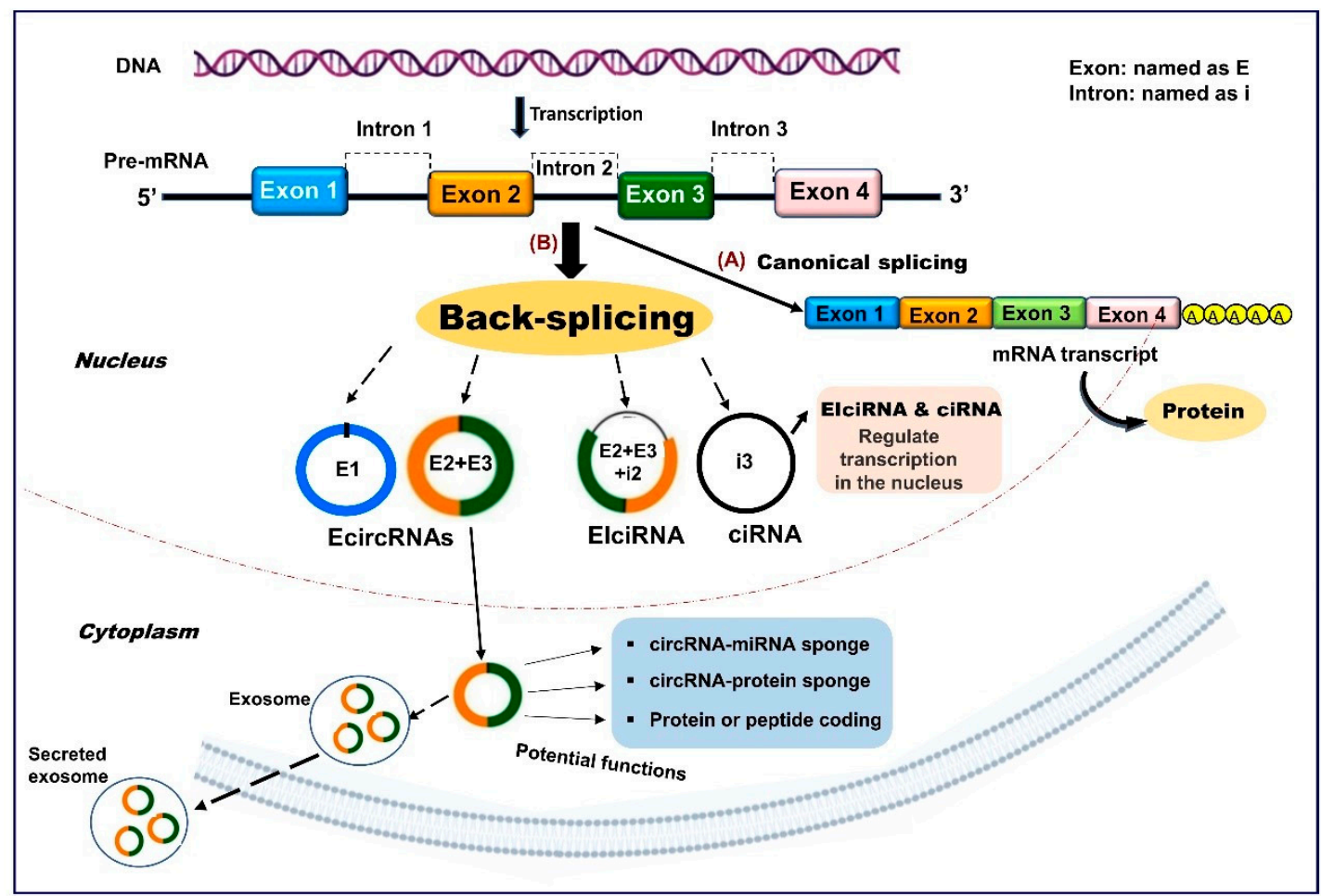

Figure 1. A simplified schematic representation of circular RNAs (circRNAs) biogenesis. (A) Pre-mRNA can undergo canonical splicing to generate a linear mRNA transcript that is subsequently translated into protein. (B) Pre-mRNA can also be spliced in the noncanonical manner "back-splicing", wherein a downstream splice donor site is joined to an upstream splice acceptor site to produce circular RNA molecules. Three different types of circRNAs can arise from different genomic positions and combinations, including: (1) exonic circRNAs (EcircRNAs), (2) exon-intron circRNAs (EIciRNAs), and (3) circular intronic RNAs (ciRNAs). The formation mechanisms and potential functions of these circRNA types are discussed in the text.

\subsection{Properties of circRNAs}

According to the published literature, circRNAs share several features. They are highly stable in cells due to their unique structure, and with most species, the average half-life period of these molecules is about $48 \mathrm{~h}$ which is much longer than that of mRNAs $(10 \mathrm{~h})$ [16]. However, this may not be the case for exonic circRNAs in serum, presumably due to circulating RNA endonucleases. circRNAs are evolutionarily conserved among species, diverse, often show tissue or development stage-specific expression patterns and have determined subcellular localization [16-18]. The abundance of circRNAs relative to their linear RNA counterparts varies between cell types [19]. They are abundant in exosomes and often found in extracellular fluid (like saliva, blood, and urine) with an expression level ten times higher than that of linear mRNAs [20]. Their size ranges from hundreds to thousands of nucleotides, while most of these RNA species in mammals and plants are hundreds of nucleotides [16,21] and usually contain between one and five exons [18].

\subsection{Biological Functions of circRNAs}

\subsection{1. circRNAs Can Function as miRNA Sponges}

Although the exact function of most circRNAs is still ambiguous, several studies have indicated that circRNAs may control multiple biological processes via a variety of mechanisms. They can serve as miRNA sponges, which in turn influence target mRNA translation $[18,22]$. In other words, circRNAs that contain miRNA recognition elements (MREs) can interact with miRNAs by stable complementary base pairing $[23,24]$ to inhibit their activity, and thus, effectively alter their role in 
the posttranscriptional regulation of target gene expression. To cite a few examples, the cerebellar degeneration-related antigen 1-antisense circRNA (CDR1as, also known as ciRS-7), which is highly expressed in the mammalian brain and upregulated during neuronal development [25], contains up to 74 binding sites for the miR-7 and can act as a decoy or sponge for this miRNA [18]. In human cells, knockdown of CDR1as expression suppresses miR-7 expression and affects insulin secretion, cell proliferation and the pathobiology of myocardial infarction [26-28]. Likewise, sex determining region Y (SRY)-derived circRNA (circSRY), which is expressed in murine testis and harbors 16 miR-138 conserved binding sites, has also been shown to act as a miRNA sponge $[23,24]$ resulting in gene expression dysregulation.

\subsection{2. circRNAs Can Function as Transcription Regulators}

In addition to circRNAs found in the cytoplasm compartment, a fraction can accumulate inside the nucleus (ciRNAs and EIciRNAs) where they control gene expression at the transcriptional level. These intron-retaining circRNAs can interact with upstream promoters, RNA polymerase II (Pol II), and other proteins of the transcription machinery to regulate their parental gene expression in some circumstances [29-31]. For example, the ciRNAs, ci-ANKRD52 and ci-SIRT-7, are able to accumulate at transcription sites and enhance their parental genes expression, ankyrin repeat domain 52 (ANKRD52) and sirtuin 7 (RIRT7) respectively, through interaction with Pol II elongation complex [30,32]. circEIF3J and circPAIP2, two exon-intron circRNAs, are an additional example of circRNAs exclusively localized in the nucleus and able to regulate the transcription of their parental genes through interactions with U1 small nuclear RNA (snRNA), Pol II, and promoter regions [29]. In addition, circRNAs may also be implicated in alternative splicing regulating transcription, translation, and miRNA levels [18].

\subsection{3. circRNAs Can Act as RNA-Binding Protein Sponges or Decoys}

circRNAs can also serve as protein decoys or antagonists to influence gene expression and cellular function. In line with this, RNA-binding proteins (RBPs) harbor specific sequences to bind their specific RNA targets and regulate several cellular and molecular processes [33]. The interaction between circRNAs and RBPs was explored recently and was shown to affect the fate of their target mRNAs. For instance, circular RNA poly (A) binding protein nuclear 1 (circPABPN1) can recruit the RBP Human antigen R (HuR) to suppress its interaction with PABPN1 mRNA, which leads to reduced PABPN1 translation [33]. In vascular tissue, circular antisense noncoding RNA in the INK4 locus (circANRIL) sequesters pescadillo homologue 1 (PES1) which is an essential 60S-preribosomal assembly factor to impair rRNA maturation, resulting in apoptosis [34]. circFoxo3 interacts with p21 and cyclin-dependent kinase (CDK2) to form a complex that impacts cell survival and proliferation [31]. Additionally, several circRNAs have been shown to bind, store, and even insulate RBPs from specific subcellular sites [35], but the exact mechanism of dynamic interactions between circRNA transcripts and various proteins remains partially explored. Advances in this field may come from the emergence of novel high-throughput experimental technologies and innovative machine learning models for predicting RBP-binding sites on RNAs. In this context, a new computational model designated CircSLNN is now available to predict potential RBP sites in circRNA sequences [36].

\subsection{4. circRNAs May Encode Proteins or Peptides}

Although circRNAs have been defined as a distinct class of ncRNAs that do not code for proteins, intriguingly, recent studies have indicated that some circRNAs may have an unexpected protein-coding potential [37], when recognized by ribosomes in the presence of internal ribosome entry sites (IRESs) [38,39]. Like IncRNAs, certain circRNAs may contain putative short open reading frames (ORFs) with the capacity to encode small peptides [40]. There are multiple examples in the literature of specific circRNAs that can encode peptides or proteins. For instance, circ-ZNF609 can make a protein functioning in muscle development [41]. The $\operatorname{circ} \beta$-catenin that is derived from the $\beta$-catenin gene has been shown to encode a novel 370-amino acid $\beta$-catenin isoform [42]. Zhang et al. reported that 
the circular form of LINC-PINT (Long Intergenic Non-Protein Coding RNA, P53 Induced Transcript) can be translated into a small peptide to suppress glioblastoma cell proliferation [43]. However, in which condition is circRNAs translation prevalent and what role do the putative peptide/protein products play are important questions that must be asked. In addition, even though several mechanisms for circRNAs translation have been proposed $[39,43]$, further in-depth studies are required which may help to unravel the mystery of these RNAs species. Moreover, if the translation process of circRNAs turns out to be true, this could represent additional evidence that these transcripts are functional molecules. Such a new perspective could be considered as the first step to understanding the hidden human proteome encoded by ncRNAs and highlight specific avenues for future research.

\subsubsection{Other Proposed Functions of circRNAs}

In addition to the above-mentioned functions, it has been suggested that circRNAs found in these extracellular vesicles could serve as essential messengers for inter-cellular/inter-tissue cross-talk as released exosomes can be taken up by other cells $[15,44,45]$. It has also been indicated that circRNA can serve to protect mRNA from degradation. As an example, a circRNA named circPan3 appears to protect mRNAs encoding the cytokine receptor subunit IL-13R $\alpha$ (IL13ral) from an mRNA decay protein, K-homology splicing regulatory protein (KSRP), and promote the production of IL-13R $\alpha 1$ in crypt mouse multipotent intestinal stem cells [46]. Other studies have indicated that circRNAs could play a role in the storage, sorting, and localization of miRNAs [47]. Nevertheless, despite the significant progress toward understanding circRNAs molecular biology, a unified explanation for the function of most of these RNA species is still lacking and knowledge of their regulatory mechanisms remains rudimentary. Additionally, it is not known how circRNAs are retained in the nucleus or exported to the cytoplasm. All these limitations may slow advances to develop circRNAs as biomarkers and therapeutic tools for specific diseases.

\section{4. circRNAs in Metabolic Diseases}

Although the state of the current knowledge of circRNAs biology is at a very early stage, mounting evidence points to their role as master regulators of gene expression in many diseases including metabolic disorders. In accordance with this observation, a growing number of studies revealed the dysregulation of circRNAs in association with the pathophysiology of several diseases such as diabetes, hypertension, cardiovascular diseases (CVD), and other metabolic perturbations [48,49]. For example, the aberrant expression of certain circRNAs was associated with the development of diabetes. In islet cells, the overexpression of CDR1as significantly increased insulin mRNA level and granule secretion in $\beta$ cells via CDR1as/miR-7 pathway [27]. In heart function, existing evidence showed that the heart-related circRNA (HRCR) can prevent cardiac hypertrophy and heart failure by acting as an endogenous sponge for miR-223 [50]. Furthermore, circRNA myocardial infarction-associated circular RNA (MICRA) showed prognostic significance as a biomarker for risk stratification of heart failure after myocardial infarction [51]. circZNF609, one of the abundantly expressed circRNAs in endothelial cells, was significantly upregulated upon hypoxia and high glucose exposure in vitro, as well as in patients affected by diabetes mellitus, hypertension, and coronary heart disease [52,53]. In atherosclerosis, CDKN2B-AS1 or ANRIL is perhaps one of the molecularly best-studied circRNAs. Based on previous studies, circANRIL is an antisense circRNA generated by the 9p21 locus, whose single nucleotide polymorphisms (SNPs) have been linked to genome-wide association studies (GWAS) on atherosclerotic vascular disease, as well as to type 2 diabetes mellitus (T2DM) and other diseases [34,54]. Additionally, circANRIL has been found to confer atheroprotection by controlling rRNA maturation and modulating pathways of atherogenesis [34]. There is also growing evidence that circRNAs are closely linked to non-alcoholic fatty liver disease (NAFLD), a disorder that is caused by a plethora of factors including hepatic lipid accumulation, adipose tissue and mitochondrial dysfunction, a high-fat diet, obesity, a chronic inflammatory state, insulin resistance (IR), and genetic and epigenetic factors [48,55]. Finally, although more functional circRNAs are being 
gradually identified and some advances have been achieved in atherosclerosis, diabetes, hypertension, and CVD, the role of circRNAs in connection with dysregulated adipogenesis and obesity remains largely elusive and needs to be explored further. The next section focuses mainly on relevant circRNA networks implicated in obesity from an epigenetic perspective.

\section{3. circRNAs in Obesity}

\subsection{Obesity}

Obesity and its metabolic consequences have been considered as one of the most threatening health burdens of modern times. Multiple investigations have brought forward evidence that obesity is a complex condition with multiple etiologies which develop as a joint effect of a variety of factors such as biological, genetic, social, environmental, and behavioral determinants [56,57]. The pathogenesis of overweight and obesity has been associated with altered adipose tissue metabolism and represents an important driving factor for many human metabolic disturbances and serious comorbidities including T2DM, CVD, and certain types of cancer [58,59]. In addition to its association with chronic diseases, obesity is also thought to increase the risk of developing severe forms of respiratory failure. Indeed, emerging studies revealed a strong association between obesity and the ongoing pandemic of coronavirus disease (COVID-19), which is caused by infection with severe acute respiratory syndrome coronavirus 2 (SARS-CoV-2) $[60,61]$. Thus, the inexorable global rise of obesity will be the toughest challenge to face and demands novel and more effective therapies.

Evidence for a large contribution of genetic variation to inter-individual differences in body mass index (BMI) comes from twin, human linkage, and association studies of large cohorts. Heritability estimates for BMI range from 31-90\% across different family studies [62], leaving the remaining variance attributed to environmental factors. However, the genetic variations, measured through familial studies, affecting obesity and variations identified at different loci, together have been estimated to explain no more than $30 \%$ of the phenotypic variation [63,64]. Hence, the "missing heritability" could be attributed to many more susceptibility factors that remain to be uncovered. One of the suggested mechanisms that may account for the missing heritability is relative to epigenetic programs. Epigenetics can be defined as acquired changes in chromatin structure through cell division that arise independently of an alteration in genomic DNA sequences [65]. Epigenetic changes are dynamic and potentially reversible marks affecting gene regulation. They can include three main categories: DNA methylation, histone modifications, and ncRNAs [66]. Ongoing research is revealing the extent of the influence of epigenetics in many diseases. In support of this claim, epigenetic differences between individuals have been found to contribute to the explanation of the monozygotic twin discordance rates for common phenotypes [67]. While DNA methylation and histone modifications occur at the level of chromatin and are well-recognized as drivers for the disease phenotype, ncRNAs represent a relatively new concept in epigenetics and act mainly at the transcriptional and posttranslational levels. Concerning obesity, studies have reported that epigenetic change plays a key role in the occurrence and development of this medical condition [68]. In addition to classical epigenetic modifications, a variety of ncRNAs have been uncovered in different cells and organs including adipose tissues, many of which are involved in the regulation of adipogenesis and other metabolic processes implying their role in the etiology of obesity [69]. While lncRNAs and miRNAs are extensively investigated in obesity biology [69-71], studies of circRNAs in this respect have just begun.

\section{2. circRNAs in Adipogenesis and Obesity}

Despite the established link between circRNAs and several metabolic diseases, investigations on the potential connection between circRNAs and adipogenesis remain rare. Currently, there are few emerging studies extending the scope of the disease-relevant role of circRNAs to obesity and underlying mechanisms. Hence, a review of examples in the literature, suggesting key regulatory 
roles of circRNAs in many biological processes associated with obesity, including adipogenesis and adipocyte differentiation, is discussed next.

Animal adipose tissue. Emerging evidence from in vitro and in vivo animal studies suggest that circRNAs are expressed in adipose tissues and may modulate adipogenesis and lipid metabolism. In this respect, Li and colleagues identified several circRNAs differentially expressed in the subcutaneous adipose tissue of Large White pigs and Laiwu pigs [72]. A further analysis revealed that circRNA_11897 was the most significantly downregulated, whereas circRNA_26852 was the most significantly upregulated; both circRNAs were significantly involved in pathways associated with adipocyte differentiation and lipid metabolism [72] (Table 1). In another study, Liu X et al. identified 850 circRNAs differentially expressed during subcutaneous adipogenesis in Chinese Erhualian pigs. These transcripts were shown to be implicated in multiple biological processes including lipid metabolic and cell differentiation processes [73]. More recently, an interesting study indicated that circSAMD4A (sterile alpha motif domain containing 4A; also named hsa_circ_0004846) controls adipogenesis in obesity by binding to miR-138-5p [74]. In high-fat diet (HFD)-induced obese mice, mmu_circ_0000529 (the homologous mouse circRNA for circSAMD4A) knockdown reversed the associated weight gain, reduced food intake, lowered body fat, and increased energy expenditure. It is worth noting that these mice also exhibited increased insulin sensitivity and glucose tolerance [74]. Mechanistically, in vitro experiments showed that circSAMD4A can bind to miR-138-5p and act as a miRNA sponge to subsequently regulate EZH2 expression [74]. In humans, circSAMD4A was found to be significantly upregulated in obese compared to lean individuals and its level of expression notably correlated with poor prognosis in obese patients [74] (Figure 1). Functional analysis confirmed that circSAMD4A overexpression can regulate preadipocytes differentiation and effectively predict obese human outcomes. A recently published report indicated that the expression of two circRNAs, 19:45387150|45389986 and 21:6969877|69753491, was strongly correlated with fat deposition associated genes in Chinese Buffalo (Bubalus bubalis) [75]. In the same context, Zhang et al. identified six circRNAs, novel_circ_0009127, novel_circ_0000628, novel_circ_0011513, novel_circ_0010775, novel_circ_0006981, and novel_circ_0001494 that were related to Yac (Bos grunniens) adipogenesis [76]. In cattle adipocytes, circFUT10 was found to promote adipocyte proliferation and inhibit adipocyte differentiation via sponging let-7 binding of let-7c [77]. Moreover, ciRS-7/CDR1as expression levels were decreased both in ob/ob and $\mathrm{db} / \mathrm{db}$ mice, which were severely obese due to lack of leptin or the leptin receptor, respectively [78]. Collectively, these findings suggest that circRNAs may participate in adipocyte differentiation and adipose tissue formation through post-transcriptional regulation.

Human adipose tissue. The past two years have witnessed a significant increase in the number of studies determining the function of circRNAs in human adipogenesis and obesity. In a study involving visceral adipogenesis, as many as 4080 circRNA species were found to be differentially expressed in human visceral preadipocytes (HPA-v) versus HPA-v that were induced to form adipocytes; among them, 2215 and 1865 circRNAs were significantly up- and downregulated, respectively [79]. Further validation experiments confirmed that hsa_circ_0136134, hsa_circ_0017650, and hsa-circRNA9227-1 were the most upregulated transcripts, suggesting their close association with visceral adipogenesis [79].

In order to screen circRNAs involved in adipogenesis and obesity, Arcinas and colleagues analyzed the transcriptome of human and mouse visceral and subcutaneous fat by RNA sequencing methods [80]. In this study, thousands of adipose circRNAs were identified to be regulated during adipogenesis. Among these, circTshz2-1 and circArhgap5-2 (the regulatory Rho GTPase activating protein 5-2) were revealed to be key regulators of adipogenesis in vitro [80]. Moreover, silencing of circArhgap5-2 in vivo resulted in inhibition of lipid droplet accumulation and downregulation of adipogenic markers suggesting that circArhgap5-2 might have a crucial role in maintaining the global adipocyte transcriptional program implicated in lipid biosynthesis and metabolism. Interestingly, the proadipogenic function of circArhgap5-2 was found to be conserved in human adipocytes. However, the mechanism by which circArhgap5-2 modulates adipogenesis remains to be determined. These data robustly indicate circRNAs are a contributing factor during adipogenesis and adipocyte 
metabolism. Another study by Schmidt et al. reported that the overexpression of H19, a maternally imprinted lncRNA that plays a role in lipid metabolism, protects against obesity, and improves insulin sensitivity [81]. In samples from patients with metabolic syndrome, a condition that is associated with abdominal obesity and CVD, the level of hsa_circH19 derived from H19 pre-RNA, was found to be highly increased and significantly correlated with variables of adiposity including body mass index (BMI), waist circumference, fat percent, high-density lipoprotein cholesterol (HDL-c), and visceral fat area [82]. Conversely, silencing of hsa_circH19 promoted human adipose-derived stem cells (hADSCs) adipogenic differentiation presumably through the interaction of such a circRNA with polypyrimidine tract-binding protein 1 (PTBP1) [82].

Table 1. Relevant circular RNAs involved in adipogenesis and obesity-related metabolic complications.

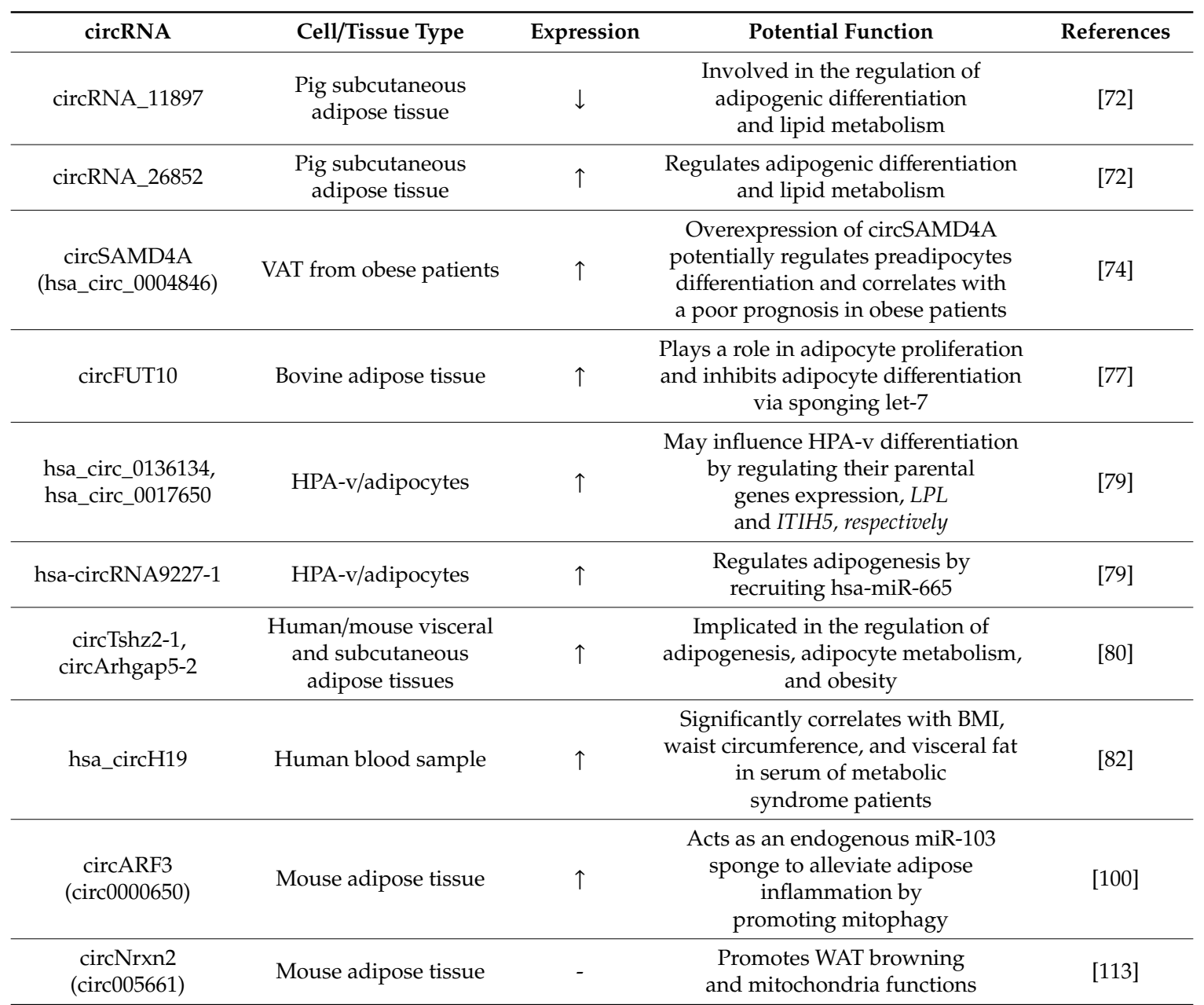

Abbreviations: circSAMD4A, sterile alpha motif domain containing 4A; BMI, body mass index; HPA-v, human preadipocytes from visceral fat tissue; ITIH5, inter-alpha-trypsin inhibitor heavy chain; LPL, lipoprotein lipase; VAT, visceral adipose tissue; WAT, white adipose tissue.

Another circRNA that has attracted substantial attention for its role in various physiopathological processes is circular antisense noncoding RNA at the INK4 locus (circANRIL). Genetic variants at the ANRIL gene have been linked with increased risk for T2DM, atherosclerotic CVD, coronary artery disease, myocardial infarction, and obesity [83-85]. Further studies have demonstrated that epigenetic regulation of ANRIL promoter methylation at birth is associated with increased cardiovascular risk [86] and later childhood adiposity [87]. Hence, perinatal methylation at ANRIL loci could be a marker for later adiposity. Collectively, the results from the above studies demonstrate that several circRNAs are differentially expressed in adipose tissue and support a significant role of these RNA species in the regulatory networks of adipogenesis. However, the precise role that circRNAs play in fat deposition 
and lipid metabolism remains elusive. Deeper understanding of molecular mechanisms controlling the expression of these RNAs species is critical to identify new targets for prevention of adipogenesis and therefore occurrence of obesity and obesity-related metabolic disorders.

\section{3. circRNAs in Obesity-Induced Insulin Resistance}

It is widely agreed that IR is strongly associated with obesity and T2DM, although not all individuals with obesity develop IR. Overwhelming evidence suggests that obesity-induced inflammation is characterized by the abundance of immune cells, which increase secretion of proinflammatory cytokines that act to perpetuate systemic inflammation, impair glucose tolerance, and cause IR leading to the development of T2DM [88]. Furthermore, the role of ncRNAs in the regulation of obesity and IR has been already reported [89,90]. For instance, miR-33 has been shown to play a crucial function in IR and obesity [91]. In humans, miR-122, miR-143-3p, and miR-652-3p have also been reportedly linked with obesity and IR and implicated in the modulation of genes and protein cascades in insulin signaling [92]. Furthermore, altered expression of lncRNAs has been associated with poor glycemic control, IR, accelerated cellular senescence, and inflammation in diabetes patients [93].

Up to now, no studies have specifically exploited the role of circRNAs in obesity-IR-T2DM settings, but this scenario will likely change in the future as alterations in many circRNAs in association with IR have been noticed. For instance, circHIPK3 has been shown to contribute to hyperglycemia and IR via sponging miR-192-5p and upregulating FOXO1 [94]. It noteworthy to mention that circHIPK3 has already been demonstrated to play a crucial role in diabetes retinas by virtue of its effect on miR-30a-3p [95]. circRNA-TFRC (transferrin receptor) has also been associated with IR, and the overexpression of TFRC can aggravate the risk of T2DM and metabolic diseases [96]. Even though these studies do not provide a direct link between potential circRNA signatures and obesity-related IR, they highlight this matter for further elucidation.

\section{4. circRNAs in Adipose Inflammation}

Chronic low-grade inflammation is now recognized as a hallmark of obesity and a key risk factor for IR and the development of T2DM [88,97]. Excess adiposity typically induces the recruitment of immune cells into fat depots. These immune cells, mainly macrophages, release proinflammatory cytokines/chemokines that can act locally but also systemically after being released into the circulation, therefore activating chronic inflammation which contributes to the development of obesity and associated metabolic disorders [98]. Thus, better exploring white adipose tissue inflammation mechanisms and pinpointing the immunological events occurring in this tissue will provide insights into the pathophysiological role of inflammation in obesity and help to manage obesity related diseases.

Although there has been some progress in the role of ncRNAs in adipogenesis, the significance of these RNAs in adipose inflammation remains elusive. The implication of some ncRNAs in the regulation of obesity-associated inflammation has been suggested previously. As an example, Stapleton et al. identified a novel lncRNA named macrophage inflammation-suppressing transcript (MIST) which was downregulated in both peritoneal macrophages and adipose tissue macrophages from high-fat diet-fed obese mice [99]. Moreover, human ortholog of MIST was found to be expressed in human adipose tissue macrophages and inversely correlated with obesity and IR. Recently, an elegant study by Arcinas and colleagues demonstrated a general decrease of circRNA transcripts in adipose tissue of HFD mice, suggesting that inflammation may affect circRNA biogenesis [80]. This assumption was based on the observation that treatment of differentiated primary mouse subcutaneous adipocytes with soluble tumor necrosis factor (TNF)- $\alpha$ led to significant reduction in circRNAs expression [80].

In another study, it was observed that circARF3 (ADP-ribosylation factor 3) functions as an endogenous miR-103 sponge to inhibit miR-103 activity, resulting in an increase of TNF receptor-associated factor 3 (TRAF3) expression and accordingly alleviates inflammation in mouse adipose tissue [100]. Subsequent experiments provided more consistent support for the notion 
that circARF3 is involved in inflammation as adipose inflammation was improved because TRAF3 blocked the nuclear factor $\mathrm{KB}$ (NF-kB)-signaling pathway, promoted mitophagy, and suppressed NOD-like receptor family, pyrin domain-containing protein 3 (NLRP3) inflammasome activation and inflammatory cytokine release [100]. On the contrary, another study reported that myeloid cell TRAF3 promotes metabolic inflammation, insulin resistance, and hepatic steatosis in obesity [101]. These authors further showed that myeloid TRAF3 may have anti-inflammatory and proinflammatory activities in lean and obese mice respectively, suggesting that, in obesity progression, myeloid TRAF3 functionally switches its activity from anti-inflammatory to proinflammatory modes.

Obesity and inflammation have been associated with several complications including T2DM, CVD, hypertension, and stroke [102]. In this perspective, Fang et al. [103] indicated that the expression of circANKRD36 was upregulated in peripheral blood leucocytes and correlated with chronic inflammation in T2DM, suggesting that circANKRD36 can be used as a potential biomarker for screening chronic inflammation in patients with T2DM. As it is estimated that a total of $80 \%$ of individuals with type 2 diabetes are obese [104], it will be interesting to evaluate the role of circANKRD36 in obesity inflammatory context.

\subsection{Role of circRNAs in White Adipose Tissue Browning}

Unlike white adipocyte tissue (WAT), which primarily stores lipids, brown adipocyte tissue (BAT) can promote energy metabolism by decreasing adiposity and increasing energy expenditure. Loss of BAT activity may contribute to obesity and development of IR. Hence, WAT browning has gained considerable attention for its potential to reverse obesity and related metabolic complications [105]. A variety of stimuli and factors such as dietary factors, cold exposure, nuclear receptors and ligands, certain drugs, and some ncRNAs can induce a phenotypic switch in adipose tissue from WAT to BAT and regulate browning [106-109]. Although significant progress has been made in understanding the epigenetic molecular mechanisms of WAT browning, the role of ncRNAs, a novel class of regulatory determinants in this context is still mostly unknown.

So far, several miRNAs have been identified and characterized to govern WAT browning process $[107,110]$. Moreover, a class of lncRNAs has also been shown to regulate brown adipogenesis $[80,111]$. With respect to the potential implication of circRNAs in such a process, studies are only emerging. In this respect, Zhang et al. reported that plasma exosomal ciRS-133 derived from gastric cancer patient cells promotes WAT browning by targeting the miR-133/PRDM16 pathway [112]. In the same manner, circNrxn2 was shown to promote WAT browning by acting as a miR-103 sponge (Table 1) and enhance the expression levels of fibroblast growth factor 10 (FGF10) in HFD mice [113]. Nonetheless, these pilot studies provide a great potential therapeutic strategy to reduce the excessive energy stores in obesity. Therefore, further investigation of the role of circRNAs in WAT browning program is needed.

\section{Conclusions and Future Perspectives}

circRNAs are increasingly being recognized to play essential roles in several diseases including metabolic disorders. They are also emerging as a novel regulatory layer in adipogenesis and lipid metabolism involved in the development of obesity. Yet a number of key questions remain: i) While the studies discussed above have confirmed that circRNAs display altered expression patterns in adipose tissue and obese individuals, the cell types and tissue origin of circRNAs in obesity are not yet fully explored. This is very challenging because obesity is a complicated condition involving many tissues and organs including the muscle, pancreas, liver, and adipose tissue. In addition, there is growing evidence that WAT is heterogeneous, and adipocytes are only part of the adipose deposit. Furthermore, different types of adipocytes have differing metabolisms and their ability to communicate with other metabolic organs through sending out various signaling molecules and possibly ncRNAs may contribute to the regulation of systemic energy homeostasis differently $[114,115]$. Therefore, part of the solution to these hurdles may be achieved by 1) discriminating the cellular origin of secreted 
circRNAs in order to identify those involved in tissue function in health and dysfunction in disease; 2) identifying potential circRNAs mediating inter-organ metabolic communication as well as those that my impact homeostasis in case of organ failure; and 3) characterizing natural circRNAs carriers to reach distant organs. ii) The potential role of exosomal circRNA signature in the development of obesity and related complications remains largely unknown. Several studies found that ncRNAs in secreted exosomes can be transferred to target tissues or cells to exert function [116]. Furthermore, adipocytes have been shown to produce and release vesicles containing genetic material to communicate with neighboring cells within WAT or facilitate metabolic organs crosstalk [117,118]. Clear and convincing evidence of this phenomenon is provided by a recent study showing that adipose tissue can release miRNAs in the circulation [115] which can regulate gene expression in other distant metabolic organs. Moreover, adipose tissue macrophages in obese mice can secrete miRNA-containing exosomes, which cause glucose intolerance and IR when administered to lean mice [116]. With respect to circRNAs found in adipose tissues, they may also be released to the circulation inside macrovesicles and have functions in target organs. In support of this assumption, a recent report indicated that adipose-derived exosomes mediate the delivery of circRNAs and promote the tumorigenesis of hepatocellular carcinoma (HCC) by regulating the deubiquitination-related miR-34a/USP7 axis [119]. As stated above, a study by Zhang et al. revealed that exosomal circRNA derived from gastric tumor promotes white adipose browning by targeting miR-133 [112]. Moreover, exosomal circRNAs have been suggested as circulating biomarkers for the diagnosis of cancer as they have been shown to discriminate patients with cancer from healthy controls [120]. However, how many copies of circRNA molecules these exosomes harbor needs to be evaluated. Further, more in vitro and in vivo modeling of exosome-mediated circRNA communication along with development of sensitive bioinformatic methods and mathematical mass-action models to capture all circRNA-target interactions, will undoubtedly provide insight into the function of these exosomal RNA species. Further stoichiometric analysis is required to better explore circRNA-miRNA and circRNA-RBP interactions. Success in addressing all these issues may clarify the controversy surrounding the sponging function of circRNAs. iii) circRNAs have also been reported to bind, store, and even insulate RBPs from specific subcellular sites or act as competitive elements to influence the function of RBPs. However, to my knowledge, no one has specifically interrogated the role of circRNA-RBP axis in adipose tissue and obesity processes. Several RBPs have been reported as adipocyte regulators by affecting different aspects of RNA processing. For example, the RNA-binding protein PSPC1 (paraspeckle component 1) has been identified as an adipogenic factor that directly interacts with adipocyte RNAs and promotes their export from the nucleus to the cytosol [121]. KH-type splicing regulatory protein (KSRP) targeted deletion has been shown to promote browning of WAT through reduction in miR-150 expression [122]. RNA-binding protein insulin growth factor 2 mRNA-binding protein 2 (IMP2) controls energy metabolism by suppressing mRNA translation of mitochondrial proton transporter uncoupling protein 1 (UCP1) and other mitochondrial mRNAs in BAT [123]. More interesting, two recently published studies reported that the RNA-binding protein HuR protects against obesity and IR [124,125]. However, it remains unclear as to whether this mechanism involves an interaction with circRNAs or not. As stated before, circRNAs containing RBP binding sites may serve as sponges or decoys for these proteins and are thus predicted to function as robust posttranscriptional regulators of gene expression. Unfortunately, the biochemical stoichiometry between circRNAs-miRNAs and circRNAs-RBPs is not yet well determined in adipose tissue. The relative abundance of circRNAs, miRNAs, and RBPs as well as their epigenetics modifications (e.g., hypermethylation) and stoichiometry analysis must be considered for the physiological relevance of any sequestration effect and cross-regulation as it may support the concept that circRNAs can serve as protein sponges or decoys to influence their cellular functions. Nevertheless, regardless of their function, the potential use of circRNAs as biomarkers for obesity and metabolic diseases remains a great promise. iv) Although the existing studies support the potential value of circRNAs in the diagnosis and therapeutics of obesity, it is too early to consider the feasibility of these molecules as biomarkers and disease therapeutic targets in a clinical obesity 
setting. As of now, the effectiveness of circRNAs has not been explored in large, clinically controlled, and conclusive cohorts, nor their mechanisms of action extensively studied. In addition, potential toxicity, reaction to drugs, immune response, accumulation to other tissues, and adequate carriers of circRNAs remain unknown. Nevertheless, a greater understanding of these issues is required if we are to see circRNAs clinical translation becoming a reality. v) Since obesity is a context of metabolic stress associated with dysfunction of numerous biological processes including adipose tissue dynamic, lipid metabolism, insulin signaling pathways, adipokines secretion, systemic inflammation, and mitochondrial activities, it is not clear how all these parameters might affect the machinery of circRNAs biogenesis, secretion, transfer, and mode of action. vi) Last but not least, given the complexity of obesity pathomechanisms, relying on the pattern of a single circRNA for diagnosis and treatment obesity may not be biologically most relevant and sufficiently specific to provide a clinical utility. Rather, one should consider a multi-markers approach that combines candidate circRNAs/signatures, miRNAs, and RBPs which may be highly discriminative, accurate, and efficient in predicting obesity and associated metabolic perturbations.

To sum up, circRNAs have recently emerged as a class of ncRNAs with multifaceted roles in the cell. Emerging evidence from in vitro and in vivo experimental studies indicates that circRNAs are involved in the regulation of adipogenesis and obesity. However, the ongoing efforts to better understand the role of circRNAs in adipose tissue and metabolics must include the above-mentioned considerations as they may help accelerate their clinical research.

Funding: No funding was received for this article.

Conflicts of Interest: The author declares no conflict of interest.

\section{References}

1. Wright, M.W.; Bruford, E.A. Naming 'junk': human non-protein coding RNA (ncRNA) gene nomenclature. Hum. Genomics 2011, 5, 90-98. [CrossRef] [PubMed]

2. Mercer, T.R.; Gerhardt, D.J.; Dinger, M.E.; Crawford, J.; Trapnell, C.; Jeddeloh, J.A.; Mattick, J.S.; Rinn, J.L. Targeted RNA sequencing reveals the deep complexity of the human transcriptome. Nat. Biotechnol. 2011, 30, 99-104. [CrossRef] [PubMed]

3. Eddy, S.R. Non-coding RNA genes and the modern RNA world. Nat. Rev. Genet. 2001, 2, 919-929. [CrossRef]

4. Diederichs, S.; Bartsch, L.; Berkmann, J.C.; Fröse, K.; Heitmann, J.; Hoppe, C.; Iggena, D.; Jazmati, D.; Karschnia, P.; Linsenmeier, M.; et al. The dark matter of the cancer genome: aberrations in regulatory elements, untranslated regions, splice sites, non-coding RNA and synonymous mutations. EMBO Mol. Med. 2016, 8, 442-457. [CrossRef] [PubMed]

5. Dragomir, M.P.; Knutsen, E.; Calin, G.A. SnapShot: Unconventional miRNA Functions. Cell 2018, 174, 1038.e1. [CrossRef]

6. Guttman, M.; Rinn, J.L. Modular regulatory principles of large non-coding RNAs. Nature 2012, 482, 339-346. [CrossRef]

7. Liu, J.; Liu, T.; Wang, X.; He, A. Circles reshaping the RNA world: from waste to treasure. Mol. Cancer 2017, 16, 58. [CrossRef]

8. Quinn, J.J.; Chang, H.Y. Unique features of long non-coding RNA biogenesis and function. Nat. Rev. Genet. 2016, 17, 47-62. [CrossRef]

9. Kagami, H.; Akutsu, T.; Maegawa, S.; Hosokawa, H.; Nacher, J.C. Determining Associations between Human Diseases and non-coding RNAs with Critical Roles in Network Control. Sci. Rep. 2015, 5, 14577. [CrossRef]

10. Jeck, W.R.; Sharpless, N.E. Detecting and characterizing circular RNAs. Nat. Biotechnol. 2014, 32, 453-461. [CrossRef]

11. Chen, L.L. The biogenesis and emerging roles of circular RNAs. Nat. Rev. Mol. Cell. Biol. 2016, 17, 205-211. [CrossRef] [PubMed]

12. Kristensen, L.S.; Andersen, M.S.; Stagsted, L.V.W.; Ebbesen, K.K.; Hansen, T.B.; Kjems, J. The biogenesis, biology and characterization of circular RNAs. Nat. Rev. Genet. 2019, 20, 675-691. [CrossRef] 
13. Li, X.; Yang, L.; Chen, L.L. The Biogenesis, Functions, and Challenges of Circular RNAs. Mol. Cell. 2018, 71 , 428-442. [CrossRef] [PubMed]

14. Zheng, Q.; Bao, C.; Guo, W.; Li, S.; Chen, J.; Chen, B.; Luo, Y.; Lyu, D.; Li, Y.; Shi, G. Circular RNA profiling reveals an abundant circHIPK3 that regulates cell growth by sponging multiple miRNAs. Nat. Commun. 2016, 7, 11215. [CrossRef] [PubMed]

15. Lasda, E.; Parker, R. Circular RNAs Co-Precipitate with Extracellular Vesicles: A Possible Mechanism for circRNA Clearance. PLoS ONE 2016, 11, e0148407. [CrossRef] [PubMed]

16. Jeck, W.R.; Sorrentino, J.A.; Wang, K.; Slevin, M.K.; Burd, C.E.; Liu, J.; Marzluff, W.F.; Sharpless, N.E. Circular RNAs are abundant, conserved, and associated with ALU repeats. RNA 2013, 19, 141-157. [CrossRef] [PubMed]

17. Salzman, J.; Gawad, C.; Wang, P.L.; Lacayo, N.; Brown, P.O. Circular RNAs are the predominant transcript isoform from hundreds of human genes in diverse cell types. PLoS ONE 2012, 7, e30733. [CrossRef]

18. Memczak, S.; Jens, M.; Elefsinioti, A.; Torti, F.; Krueger, J.; Rybak, A.; Maier, L.; Mackowiak, S.D.; Gregersen, L.H.; Munschauer, M.; et al. Circular RNAs are a large class of animal RNAs with regulatory potency. Nature 2013, 495, 333-338. [CrossRef]

19. Salzman, J.; Chen, R.E.; Olsen, M.N.; Wang, P.L.; Brown, P.O. Correction: Cell-Type Specific Features of Circular RNA Expression. PLoS Genet. 2013, 9. [CrossRef]

20. Qu, S.; Yang, X.; Li, X.; Wang, J.; Gao, Y.; Shang, R.; Sun, W.; Dou, K.; Li, H. Circular RNA: A new star of noncoding RNAs. Cancer Lett. 2015, 365, 141-148. [CrossRef]

21. Ye, C.Y.; Chen, L.; Liu, C.; Zhu, Q.H.; Fan, L. Widespread noncoding circular RNAs in plants. New Phytol. 2015, 208, 88-95. [CrossRef] [PubMed]

22. Huang, A.; Zheng, H.; Wu, Z.; Chen, M.; Huang, Y. Circular RNA-protein interactions: Functions, mechanisms, and identification. Theranostics 2020, 10, 3503-3517. [CrossRef]

23. Wilusz, J.E.; Sharp, P.A. Molecular biology. A circuitous route to noncoding RNA. Science 2013, 340, 440-441. [CrossRef] [PubMed]

24. Hansen, T.B.; Jensen, T.I.; Clausen, B.H.; Bramsen, J.B.; Finsen, B.; Damgaard, C.K.; Kjems, J. Natural RNA circles function as efficient microRNA sponges. Nature 2013, 495, 384-388. [CrossRef] [PubMed]

25. Rybak-Wolf, A.; Stottmeister, C.; Glažar, P.; Jens, M.; Pino, N.; Giusti, S.; Hanan, M.; Behm, M.; Bartok, O.; Ashwal-Fluss, R.; et al. Circular RNAs in the Mammalian Brain Are Highly Abundant, Conserved, and Dynamically Expressed. Mol. Cell. 2015, 58, 870-885. [CrossRef] [PubMed]

26. Piwecka, M.; Glažar, P.; Hernandez-Miranda, L.R.; Memczak, S.; Wolf, S.A.; Rybak-Wolf, A.; Filipchyk, A.; Klironomos, F.; Cerda Jara, C.A.; Fenske, P.; et al. Loss of a mammalian circular RNA locus causes miRNA deregulation and affects brain function. Science 2017, 357, eaam8526. [CrossRef]

27. Xu, H.; Guo, S.; Li, W.; Yu, P. The circular RNA Cdr1as, via miR-7 and its targets, regulates insulin transcription and secretion in islet cells. Sci. Rep. 2015, 5, 12453. [CrossRef]

28. Geng, H.-H.; Li, R.; Su, Y.-M.; Xiao, J.; Pan, M.; Cai, X.-X.; Ji, X.-P. The Circular RNA Cdr1as Promotes Myocardial Infarction by Mediating the Regulation of miR-7a on Its Target Genes Expression. PLoS ONE 2016, 11, e0151753. [CrossRef]

29. Li, Z.; Huang, C.; Bao, C.; Chen, L.; Lin, M.; Wang, X.; Zhong, G.; Yu, B.; Hu, W.; Dai, L.; et al. Exon-intron circular RNAs regulate transcription in the nucleus. Nat. Struct. Mol. Biol. 2015, 22, 256-264. [CrossRef]

30. Zhang, Y.; Zhang, X.O.; Chen, T.; Xiang, J.F.; Yin, Q.F.; Xing, Y.H.; Zhu, S.; Yang, L.; Chen, L.L. Circular intronic long noncoding RNAs. Mol. Cell 2013, 51, 792-806. [CrossRef] [PubMed]

31. Du, W.W.; Yang, W.; Liu, E.; Yang, Z.; Dhaliwal, P.; Yang, B.B. Foxo3 circular RNA retards cell cycle progression via forming ternary complexes with p21 and CDK2. Nucleic Acids Res. 2016, 44, 2846-2858. [CrossRef] [PubMed]

32. Zhao, Z.J.; Shen, J. Circular RNA participates in the carcinogenesis and the malignant behavior of cancer. RNA Biol. 2017, 14, 514-521. [CrossRef] [PubMed]

33. Abdelmohsen, K.; Panda, A.C.; Munk, R.; Grammatikakis, I.; Dudekula, D.B.; De, S.; Kim, J.; Noh, J.H.; Kim, K.M.; Martindale, J.L.; et al. Identification of HuR target circular RNAs uncovers suppression of PABPN1 translation by CircPABPN1. RNA Biol. 2017, 14, 361-369. [CrossRef] [PubMed]

34. Holdt, L.M.; Stahringer, A.; Sass, K.; Pichler, G.; Kulak, N.A.; Wilfert, W.; Kohlmaier, A.; Herbst, A.; H Northoff, B.H.; Nicolaou, A.; et al. Circular non-coding RNA ANRIL modulates ribosomal RNA maturation and atherosclerosis in humans. Nat. Commun. 2016, 7, 12429. [CrossRef] 
35. Du, W.W.; Zhang, C.; Yang, W.; Yong, T.; Awan, F.M.; Yang, B.B. Identifying and Characterizing circRNA-Protein Interaction. Theranostics 2017, 7, 4183-4191. [CrossRef]

36. Ju, Y.; Yuan, L.; Yang, Y.; Zhao, H. CircSLNN: Identifying RBP-Binding Sites on circRNAs via Sequence Labeling Neural Networks. Front. Genet. 2019, 10, 1184. [CrossRef]

37. Lei, M.; Zheng, G.; Ning, Q.; Zheng, J.; Dong, D. Translation and functional roles of circular RNAs in human cancer. Mol. Cancer 2020, 19, 30. [CrossRef]

38. Chen, C.; Sarnow, P. Initiation of protein synthesis by the eukaryotic translational apparatus on circular RNAs. Science 2015, 268, 415-417. [CrossRef]

39. Pamudurti, N.R.; Bartok, O.; Jens, M.; Ashwal-Fluss, R.; Stottmeister, C.; Ruhe, L.; Hanan, M.; Wyler, E.; Perez-Hernandez, D.; Ramberger, E.; et al. Translation of CircRNAs. Mol. Cell 2017, 66, 9.e7-21.e7. [CrossRef]

40. Yang, Y.; Fan, X.; Mao, M.; Song, X.; Wu, P.; Zhang, Y.; Jin, Y.; Yang, Y.; Chen, L.L.; Wang, Y.; et al. Extensive translation of circular RNAs driven by N6-methyladenosine. Cell Res. 2017, 27, 626-641. [CrossRef]

41. Legnini, I.; Di Timoteo, G.; Rossi, F.; Morlando, M.; Briganti, F.; Sthandier, O.; Fatica, A.; Santini, T.; Andronache, A.; Wade, M.; et al. Circ-ZNF609 Is a Circular RNA that Can Be Translated and Functions in Myogenesis. Mol. Cell 2017, 66, 22.e9-37.e9. [CrossRef] [PubMed]

42. Liang, W.C.; Wong, C.W.; Liang, P.P.; Shi, M.; Cao, Y.; Rao, S.T.; Tsui, S.K.; Waye, M.M.; Zhang, Q.; Fu, W.M.; et al. Translation of the circular RNA circbeta-catenin promotes liver cancer cell growth through activation of the Wnt pathway. Genome Biol. 2019, 20, 84. [CrossRef] [PubMed]

43. Zhang, M.; Zhao, K.; Xu, X.; Yang, Y.; Yan, S.; Wei, P.; Liu, H.; Xu, J.; Xiao, F.; Zhou, H.; et al. A peptide encoded by circular form of LINC-PINT suppresses oncogenic transcriptional elongation in glioblastoma. Nat. Commun. 2018, 9, 4475. [CrossRef] [PubMed]

44. Wang, Y.; Liu, J.; Ma, J.; Sun, T.; Zhou, Q.; Wang, W.; Wang, G.; Wu, P.; Wang, H.; Jiang, L.; et al. Exosomal circRNAs: Biogenesis, effect and application in human diseases. Mol. Cancer 2019, 18, 116. [CrossRef] [PubMed]

45. Preußer, C.; Hung, L.H.; Schneider, T.; Schreiner, S.; Hardt, M.; Moebus, A.; Santoso, S.; Bindereif, A. Selective release of circRNAs in platelet-derived extracellular vesicles. J. Extracell. Vesicles 2018, 7, 1424473. [CrossRef]

46. Zhu, P.; Zhu, X.; Wu, J.; He, L.; Lu, T.; Wang, Y.; Liu, B.; Ye, B.; Sun, L.; Fan, D.; et al. IL-13 secreted by ILC2s promotes the self-renewal of intestinal stem cells through circular RNA circPan3. Nat. Immunol. 2019, 20, 183-194. [CrossRef]

47. Van Rossum, D.; Verheijen, B.M.; Pasterkamp, R.J. Circular RNAs: Novel Regulators of Neuronal Development. Front. Mol. Neurosci. 2016, 9, 74. [CrossRef]

48. Zaiou, M. Circular RNAs as Potential Biomarkers and Therapeutic Targets for Metabolic Diseases. Adv. Exp. Med. Biol. 2019, 1134, 177-191.

49. Zaiou, M. Circular RNAs in hypertension: Challenges and clinical promise. Hypertens. Res. 2019, 42, 1653-1663. [CrossRef]

50. Wang, K.; Long, B.; Liu, F.; Wang, J.X.; Liu, C.Y.; Zhao, B.; Zhou, L.Y.; Sun, T.; Wang, M.; Yu, T.; et al. A circular RNA protects the heart from pathological hypertrophy and heart failure by targeting miR-223. Eur. Heart J. 2016, 37, 2602-2611. [CrossRef]

51. Salgado-Somoza, A.; Zhang, L.; Vausort, M.; Devaux, Y. The circular RNA MICRA for risk stratification after myocardial infarction. Int. J. Cardiol. Heart Vasc. 2017, 17, 33-36. [CrossRef] [PubMed]

52. Zaiou, M. circRNAs Signature as Potential Diagnostic and Prognostic Biomarker for Diabetes Mellitus and Related Cardiovascular Complications. Cells 2020, 9, 659. [CrossRef] [PubMed]

53. Liu, C.; Yao, M.D.; Li, C.P.; Shan, K.; Yang, H.; Wang, J.J.; Yan, B. Silencing of Circular RNA-ZNF609 Ameliorates Vascular Endothelial Dysfunction. Theranostics 2017, 7, 2863-2877. [CrossRef] [PubMed]

54. Holdt, L.M.; Teupser, D. From genotype to phenotype in human atherosclerosis-recent findings. Curr. Opin. Lipidol. 2013, 24, 410-418. [CrossRef] [PubMed]

55. Guo, X.-Y.; Chen, J.-N.; Sun, F.; Wang, Y.-Q.; Pan, Q.; Fan, J.-G. circRNA_0046367 Prevents Hepatoxicity of Lipid Peroxidation: An Inhibitory Role against Hepatic Steatosis. Oxid. Med. Cell. Longev. 2017, 2017, 1-16. [CrossRef] [PubMed]

56. Loos, R.J.; Bouchard, C. FTO: the first gene contributing to common forms of human obesity. Obes. Rev. 2008, 9, 246-250. [CrossRef] [PubMed]

57. Rojas, J.; Arraiz, N.; Aguirre, M.; Velasco, M.; Bermúdez, V. AMPK as Target for Intervention in Childhood and Adolescent Obesity. J. Obes. 2011, 2011, 1-19. [CrossRef] [PubMed] 
58. Berezina, A.; Belyaeva, O.; Berkovich, O.; Baranova, E.; Karonova, T.; Bazhenova, E.; Brovin, D.; Grineva, E.; Shlyakhto, E. Prevalence, Risk Factors, and Genetic Traits in Metabolically Healthy and Unhealthy Obese Individuals. Biomed. Res. Int. 2015, 2015, 548734. [CrossRef]

59. Franks, P.W.; McCarthy, M.I. Exposing the exposures responsible for type 2 diabetes and obesity. Science 2016, 354, 69-73. [CrossRef]

60. Sattar, N.; McInnes, I.B.; McMurray, J.J.V. Obesity a Risk Factor for Severe COVID-19 Infection: Multiple Potential Mechanisms. Circulation 2020. [CrossRef] [PubMed]

61. Stefan, N.; Birkenfeld, A.L.; Schulze, M.B.; Ludwing, D.S. Obesity and impaired metabolic health in patients with COVID-19. Nat. Rev. Endocrinol. 2020, 23, 1-2. [CrossRef] [PubMed]

62. Min, J.; Chiu, D.T.; Wang, Y. Variation in the heritability of body mass index based on diverse twin studies: A systematic review. Obes. Rev. 2013, 14, 871-882. [CrossRef]

63. Locke, A.E.; Kahali, B.; Berndt, S.I.; Justice, A.E.; Pers, T.H.; Day, F.R.; Powell, C.; Vedantam, S.; Buchkovich, M.L.; Yang, J.; et al. Genetic studies of body mass index yield new insights for obesity biology. Nature 2015, 518, 197-206. [CrossRef] [PubMed]

64. Speakman, J.R.; Loos, R.J.F.; O’Rahilly, S.; Hirschhorn, J.N.; Allison, D.B. GWAS for BMI: A treasure trove of fundamental insights into the genetic basis of obesity. Int. J. Obes. 2018, 42, 1524-1531. [CrossRef]

65. Holliday, R. Epigenetics: An overview. Dev. Genet. 1994, 15, 453-457. [CrossRef] [PubMed]

66. Handy, D.E.; Castro, R.; Loscalzo, J. Epigenetic Modifications. Circulation 2011, 123, 2145-2156. [CrossRef] [PubMed]

67. Benayoun, B.A.; Pollina, E.A.; Brunet, A. Epigenetic regulation of ageing: linking environmental inputs to genomic stability. Nat. Rev. Mol. Cell Biol. 2015, 16, 593-610. [CrossRef] [PubMed]

68. Takada, I.; Kouzmenko, A.P.; Kato, S. Wnt and PPAR $\gamma$ signaling in osteoblastogenesis and adipogenesis. Nat. Rev. Rheumatol. 2009, 5, 442-447. [CrossRef] [PubMed]

69. Hilton, C.; Neville, M.J.; Karpe, F. MicroRNAs in adipose tissue: Their role in adipogenesis and obesity. Int. J. Obes. 2012, 37, 325-332. [CrossRef]

70. Zaiou, M.; El Amri, H.; Bakillah, A. The clinical potential of adipogenesis and obesity-related microRNAs. Nutr. Metab. Cardiovasc. Dis. 2018, 28, 91-111. [CrossRef]

71. Sun, L.; Goff, L.A.; Trapnell, C.; Alexander, R.; Lo, K.A.; Hacisuleyman, E.; Sauvageau, M.; Tazon-Vega, B.; Kelley, D.R.; Hendrickson, D.G.; et al. Long noncoding RNAs regulate adipogenesis. Proc. Natl. Acad. Sci. USA 2013, 2110, 3387-3392. [CrossRef]

72. Li, A.; Huang, W.; Zhang, X.; Xie, L.; Miao, X. Identification and Characterization of CircRNAs of Two Pig Breeds as a New Biomarker in Metabolism-Related Diseases. Cell. Physiol. Biochem. 2018, 47, 2458-2470. [CrossRef] [PubMed]

73. Liu, X.; Liu, K.; Shan, B.; Wei, S.; Li, D.; Han, H.; Wei, W.; Chen, J.; Liu, H.; Zhang, L. A genome-wide landscape of mRNAs, lncRNAs, and circRNAs during subcutaneous adipogenesis in pigs. J. Anim. Sci. Biotechnol. 2018, 9, 96. [CrossRef] [PubMed]

74. Liu, Y.; Liu, H.; Li, Y.; Mao, R.; Yang, H.; Zhang, Y.; Zhang, Y.; Guo, P.; Zhan, D.; Zhang, T. Circular RNA SAMD4A controls adipogenesis in obesity through the miR-138-5p/EZH2 axis. Theranostics 2020, 10, 4705-4719. [CrossRef] [PubMed]

75. Huang, J.; Zhao, J.; Zheng, Q.; Wang, S.; Wei, X.; Li, F.; Shang, J.; Lei, C.; Ma, Y. Characterization of Circular RNAs in Chinese Buffalo (Bubalus bubalis) Adipose Tissue: A Focus on Circular RNAs Involved in Fat Deposition. Animals 2019, 9, 403. [CrossRef] [PubMed]

76. Zhang, Y.; Guo, X.; Pei, J.; Chu, M.; Ding, X.; Wu, X.; Liang, C.; Yan, P. CircRNA Expression Profile during Yak Adipocyte Differentiation and Screen Potential circRNAs for Adipocyte Differentiation. Genes 2020, 11, 414. [CrossRef]

77. Jiang, R.; Li, H.; Yang, J.; Shen, X.; Song, C.; Yang, Z.; Wang, X.; Huang, Y.; Lan, X.; Lei, C.; et al. Circular RNA profiling reveals an abundant circFUT10 that promotes adipocytes proliferation and inhibits adipocytes differentiation via sponging let-7 family members. Mol. Ther. Nucleic Acids 2020, 20, 491-501. [CrossRef]

78. Stoll, L.; Sobel, J.; Rodriguez-Trejo, A.; Guay, C.; Lee, K.; Venø, M.T.; Kjems, J.; Laybutt, D.R.; Regazzi, R. Circular RNAs as novel regulators of $\beta$-cell functions in normal and disease conditions. Mol. Metab. 2018, 9, 69-83. [CrossRef]

79. Sun, W.; Sun, X.; Chu, W.; Yu, S.; Dong, F.; Xu, G. CircRNA expression profiles in human visceral preadipocytes and adipocytes. Mol. Med. Rep. 2020, 21, 815-821. [CrossRef] 
80. Arcinas, C.; Tan, W.; Fang, W.; Desai, T.P.; Teh, D.C.S.; Degirmenci, U.; Xu, D.; Foo, R.; Sun, L. Adipose circular RNAs exhibit dynamic regulation in obesity and functional role in adipogenesis. Nat. Metab. 2019, 1, 688-703. [CrossRef]

81. Schmidt, E.; Dhaouadi, I.; Gaziano, I.; Oliverio, M.; Klemm, P.; Awazawa, M.; Mitterer, G.; Fernandez-Rebollo, E.; Pradas-Juni, M.; Wagner, W.; et al. LincRNA H19 protects from dietary obesity by constraining expression of monoallelic genes in brown fat. Nat. Commun. 2018, 9, 3622. [CrossRef]

82. Zhu, Y.; Gui, W.; Lin, X.; Li, H. Knock-down of circular RNA H19 induces human adipose-derived stem cells adipogenic differentiation via a mechanism involving the polypyrimidine tract-binding protein 1. Exp. Cell Res. 2020, 387, 111753. [CrossRef] [PubMed]

83. Cunnington, M.S.; Santibanez Koref, M.; Mayosi, B.M.; Burn, J.; Keavney, B. Chromosome 9p21 SNPs Associated with Multiple Disease Phenotypes Correlate with ANRIL Expression. PLoS Genet. 2010, 6, e1000899. [CrossRef]

84. Congrains, A.; Kamide, K.; Ohishi, M.; Rakugi, H. ANRIL: Molecular Mechanisms and Implications in Human Health. Int. J. Mol. Sci. 2013, 14, 1278-1292. [CrossRef]

85. Kong, Y.; Sharma, R.B.; Nwosu, B.U.; Alonso, L.C. Islet biology, the CDKN2A/B locus and type 2 diabetes risk. Diabetologia 2016, 59, 1579-1593. [CrossRef]

86. Murray, R.; Bryant, J.; Titcombe, P.; Barton, S.J.; Inskip, H.; Harvey, N.C.; Cooper, C.; Lillycrop, K.; Hanson, M.; Godfrey, K.M. DNA methylation at birth within the promoter of ANRIL predicts markers of cardiovascular risk at 9 years. Clin. Epigenetics 2016, 8, 90. [CrossRef]

87. Lillycrop, K.; Murray, R.; Cheong, C.; Teh, A.L.; Clarke-Harris, R.; Barton, S.; Costello, P.; Garratt, E.; Cook, E.; Titcombe, P. ANRIL Promoter DNA Methylation: A Perinatal Marker for Later Adiposity. EBioMedicine 2017, 19, 60-72. [CrossRef] [PubMed]

88. Shoelson, S.E.; Lee, J.; Goldfine, A.B. Inflammation and insulin resistance. J. Clin. Invest. 2006, 116, $1793-1801$. [CrossRef]

89. Jones, A.; Danielson, K.M.; Benton, M.C.; Ziegler, O.; Shah, R.; Stubbs, R.S.; Das, S.; Macartney-Coxson, D. miRNA Signatures of Insulin Resistance in Obesity. Obesity 2017, 25, 1734-1744. [CrossRef]

90. Trajkovski, M.; Hausser, J.; Soutschek, J.; Bhat, B.; Akin, A.; Zavolan, M.; Heim, M.H.; Stoffel, M. MicroRNAs 103 and 107 regulate insulin sensitivity. Nature 2011, 474, 649-653. [CrossRef]

91. Price, N.L.; Singh, A.K.; Rotllan, N.; Goedeke, L.; Wing, A.; Canfrán-Duque, A.; Diaz-Ruiz, A.; Araldi, E.; Baldán, Á.; Camporez, J.P.; et al. Genetic Ablation of miR-33 Increases Food Intake, Enhances Adipose Tissue Expansion, and Promotes Obesity and Insulin Resistance. Cell Rep. 2018, 22, 2133-2145. [CrossRef] [PubMed]

92. Dahlman, I.; Belarbi, Y.; Laurencikiene, J.; Pettersson, A.M.; Arner, P.; Kulyté, A. Comprehensive functional screening of miRNAs involved in fat cell insulin sensitivity among women. Am. J. Physiol. Endocrinol. Metab. 2017, 312, E482-E494. [CrossRef] [PubMed]

93. Sathishkumar, C.; Prabu, P.; Mohan, V.; Balasubramanyam, M. Linking a role of lncRNAs (long non-coding RNAs) with insulin resistance, accelerated senescence, and inflammation in patients with type 2 diabetes. Hum. Genomics 2018, 12, 41. [CrossRef]

94. Cai, H.; Jiang, Z.; Yang, X.; Lin, J.; Cai, Q.; Li, X. Circular RNA HIPK3 contributes to hyperglycemia and insulin homeostasis by sponging miR-192-5p and upregulating transcription factor forkhead box O1. Endocr. J. 2020, 67, 379-408. [CrossRef]

95. Shan, K.; Liu, C.; Liu, B.H.; Chen, X.; Dong, R.; Liu, X.; Zhang, Y.Y.; Liu, B.; Zhang, S.J.; Wang, J.J.; et al. Circular Noncoding RNA HIPK3 Mediates Retinal Vascular Dysfunction in Diabetes Mellitus. Circulation 2017, 136, 1629-1642. [CrossRef]

96. Jäger, S.; Wahl, S.; Kröger, J.; Sharma, S.; Hoffmann, P.; Floegel, A.; Pischon, T.; Prehn, C.; Adamski, J.; Müller-Nurasyid, M.; et al. Genetic variants including markers from the exome chip and metabolite traits of type 2 diabetes. Sci. Rep. 2017, 7, 6037. [CrossRef]

97. Gregor, M.F.; Hotamisligil, G.S. Inflammatory Mechanisms in Obesity. Annu. Rev. Immunol. 2011, $29,415-445$. [CrossRef]

98. Reilly, S.M.; Saltiel, A.R. Adapting to obesity with adipose tissue inflammation. Nat. Rev. Endocrinol. 2017, 13, 633-643. [CrossRef] 
99. Stapleton, K.; Das, S.; Reddy, M.A.; Leung, A.; Amaram, V.; Lanting, L.; Chen, Z.; Zhang, L.; Palanivel, R.; Deiuliis, J.A.; et al. Novel Long Noncoding RNA, Macrophage Inflammation-Suppressing Transcript (MIST), Regulates Macrophage Activation During Obesity. Arterioscler. Thromb. Vasc. Biol. 2020, 40, 914-928. [CrossRef]

100. Zhang, Z.; Zhang, T.; Feng, R.; Huang, H.; Xia, T.; Sun, C. circARF3 Alleviates Mitophagy-Mediated Inflammation by Targeting miR-103/TRAF3 in Mouse Adipose Tissue. Mol. Ther. Nucleic Acids 2019, 14, 192-203. [CrossRef]

101. Chen, Z.; Shen, H.; Sun, C.; Yin, L.; Tang, F.; Zheng, P.; Liu, Y.; Brink, R.; Rui, L. Myeloid cell TRAF3 promotes metabolic inflammation, insulin resistance, and hepatic steatosis in obesity. Am. J. Physiol. Endocrinol. Metab. 2015, 308, E460-E469. [CrossRef] [PubMed]

102. Kaplan, M.S.; Huguet, N.; Newsom, J.T.; McFarland, B.H.; Lindsay, J. Prevalence and Correlates of Overweight and Obesity Among Older Adults: Findings From the Canadian National Population Health Survey. J. Gerontol. Ser. A Biol. Sci. Med. Sci. 2003, 58, M1018-M1030. [CrossRef] [PubMed]

103. Fang, Y.; Wang, X.; Li, W.; Han, J.; Jin, J.; Su, F.; Zhang, J.; Huang, W.; Xiao, F.; Pan, Q.; et al. Screening of circular RNAs and validation of circANKRD36 associated with inflammation in patients with type 2 diabetes mellitus. Int. J. Mol. Med. 2018, 42, 1865-1874. [CrossRef] [PubMed]

104. Bloomgarden, Z.T. American Diabetes Association Annual Meeting, 1999: diabetes and obesity. Diabetes Care 2000, 23, 118-124. [CrossRef]

105. Peirce, V.; Carobbio, S.; Vidal-Puig, A. The different shades of fat. Nature 2014, 510, 76-83. [CrossRef]

106. Kaisanlahti, A.; Glumoff, T. Browning of white fat: agents and implications for beige adipose tissue to type 2 diabetes. J. Physiol. Biochem. 2018, 75, 1-10. [CrossRef]

107. Zhang, H.; Guan, M.; Townsend, K.L.; Huang, T.L.; An, D.; Yan, X.; Xue, R.; Schulz, T.J.; Winnay, J.; Mori, M.; et al. MicroRNA-455 regulates brown adipogenesis via a novel HIF1an-AMPK-PGC1 $\alpha$ signaling network. EMBO Rep. 2015, 16, 1378-1393. [CrossRef]

108. Milet, C.; Bléher, M.; Allbright, K.; Orgeur, M.; Coulpier, F.; Duprez, D.; Havis, E. Egr1 deficiency induces browning of inguinal subcutaneous white adipose tissue in mice. Sci. Rep. 2017, 7, 16153. [CrossRef]

109. Paschos, G.K.; Tang, S.Y.; Theken, K.N.; Li, X.; Verginadis, I.; Lekkas, D.; Herman, L.; Yan, W.; Lawson, J.; FitzGerald, G.A. Cold-Induced Browning of Inguinal White Adipose Tissue Is Independent of Adipose Tissue Cyclooxygenase-2. Cell Rep. 2018, 24, 809-814. [CrossRef]

110. Chen, Y.; Siegel, F.; Kipschull, S.; Haas, B.; Fröhlich, H.; Meister, G.; Pfeifer, A. miR-155 regulates differentiation of brown and beige adipocytes via a bistable circuit. Nat. Commun. 2013, 4, 1769. [CrossRef]

111. Ding, C.; Lim, Y.C.; Chia, S.Y.; Walet, A.C.E.; Xu, S.; Lo, K.A.; Zhao, Y.; Zhu, D.; Shan, Z.; Chen, Q.; et al. De novo reconstruction of human adipose transcriptome reveals conserved lncRNAs as regulators of brown adipogenesis. Nat. Commun. 2018, 9, 1329. [CrossRef] [PubMed]

112. Zhang, H.; Zhu, L.; Bai, M.; Liu, Y.; Zhan, Y.; Deng, T.; Yang, H.; Sun, W.; Wang, X.; Zhu, K.; et al. Exosomal circRNA derived from gastric tumor promotes white adipose browning by targeting the miR-133/PRDM16 pathway. Int. J. Cancer 2019, 144, 2501-2515. [CrossRef] [PubMed]

113. Zhang, T.; Zhang, Z.; Xia, T.; Liu, C.; Sun, C. circNrxn2 Promoted WAT Browning via Sponging miR-103 to Relieve Its Inhibition of FGF10 in HFD Mice. Mol. Ther. Nucleic Acids 2019, 17, 551-562. [CrossRef]

114. Kim, J.B. Dynamic cross talk between metabolic organs in obesity and metabolic diseases. Exp. Mol. Med. 2016, 48, e214. [CrossRef] [PubMed]

115. Thomou, T.; Mori, M.A.; Dreyfuss, J.M.; Konishi, M.; Sakaguchi, M.; Wolfrum, C.; Rao, T.N.; Winnay, J.N.; Garcia-Martin, R.; Grinspoon, S.K.; et al. Adipose-derived circulating miRNAs regulate gene expression in other tissues. Nature 2017, 542, 450-455. [CrossRef] [PubMed]

116. Ying, W.; Riopel, M.; Bandyopadhyay, G.; Dong, Y.; Birmingham, A.; Seo, J.B.; Ofrecio, J.M.; Wollam, J.; Hernandez-Carretero, A.; Fu, W.; et al. Adipose Tissue Macrophage-Derived Exosomal miRNAs Can Modulate In Vivo and In Vitro Insulin Sensitivity. Cell 2017, 171, 372.e12-384.e12. [CrossRef]

117. Valadi, H.; Ekström, K.; Bossios, A.; Sjöstrand, M.; Lee, J.J.; Lötvall, J.O. Exosome-mediated transfer of mRNAs and microRNAs is a novel mechanism of genetic exchange between cells. Nat. Cell Biol. 2007, 9, 654-659. [CrossRef]

118. Deng, Z.b.; Poliakov, A.; Hardy, R.W.; Clements, R.; Liu, C.; Liu, Y.; Wang, J.; Xiang, X.; Zhang, S.; Zhuang, X.; et al. Adipose Tissue Exosome-Like Vesicles Mediate Activation of Macrophage-Induced Insulin Resistance. Diabetes 2009, 58, 2498-2505. [CrossRef] 
119. Zhang, H.; Deng, T.; Ge, S.; Liu, Y.; Bai, M.; Zhu, K.; Fan, Q.; Li, J.; Ning, T.; Tian, F.; et al. Exosome circRNA secreted from adipocytes promotes the growth of hepatocellular carcinoma by targeting deubiquitination-related USP7. Oncogene 2018, 38, 2844-2859. [CrossRef]

120. Li, Y.; Zheng, Q.; Bao, C.; Li, S.; Guo, W.; Zhao, J.; Chen, D.; Gu, J.; He, X.; Huang, S. Circular RNA is enriched and stable in exosomes: A promising biomarker for cancer diagnosis. Cell Res. 2015, 25, 981-984. [CrossRef]

121. Wang, J.; Rajbhandari, P.; Damianov, A.; Han, A.; Sallam, T.; Waki, H.; Villanueva, C.J.; Lee, S.D.; Nielsen, R.; Mandrup, S.; et al. RNA-binding protein PSPC1 promotes the differentiation-dependent nuclear export of adipocyte RNAs. J. Clin. Invest. 2017, 127, 987-1004. [CrossRef] [PubMed]

122. Chou, C.F.; Lin, Y.Y.; Wang, H.K.; Zhu, X.; Giovarelli, M.; Briata, P.; Gherzi, R.; Garvey, W.T.; Chen, C.Y. KSRP Ablation Enhances Brown Fat Gene Program in White Adipose Tissue Through Reduced miR-150 Expression. Diabetes 2014, 63, 2949-2961. [CrossRef] [PubMed]

123. Dai, N.; Zhao, L.; Wrighting, D.; Krämer, D.; Majithia, A.; Wang, Y.; Cracan, V.; Borges-Rivera, D.; Mootha, V.K.; Nahrendorf, M.; et al. IGF2BP2/IMP2-Deficient Mice Resist Obesity through Enhanced Translation of Ucp1 mRNA and Other mRNAs Encoding Mitochondrial Proteins. Cell Metab. 2015, 21, 609-621. [CrossRef] [PubMed]

124. Li, J.; Gong, L.; Liu, S.; Zhang, Y.; Zhang, C.; Tian, M.; Lu, H.; Bu, P.; Yang, J.; Ouyang, C.; et al. Adipose HuR protects against diet-induced obesity and insulin resistance. Nat. Commun. 2019, 10, 2375. [CrossRef]

125. Siang, D.T.C.; Lim, Y.C.; Kyaw, A.M.M.; Win, K.N.; Chia, S.Y.; Degirmenci, U.; Hu, X.; Tan, B.C.; Walet, A.C.E.; Sun, L.; et al. The RNA-binding protein HuR is a negative regulator in adipogenesis. Nat. Commun. 2020, 11, 213. [CrossRef]

(C) 2020 by the author. Licensee MDPI, Basel, Switzerland. This article is an open access article distributed under the terms and conditions of the Creative Commons Attribution (CC BY) license (http://creativecommons.org/licenses/by/4.0/). 